Denise Ferreira da Silva

University of Califomia, Sa n Diego

\title{
À brasileira: racialidade e a escrita de um desejo destrutivo
}

\begin{abstract}
Resumo: Se o erotismo, como afirma Bataille, diferencia a sexualidade humana - conforme institui o sujeito moderno como efeito do desejo - está corretamente classificado entre as análises críticas das condições de produção dos sujeitos modernos. Por isso, neste artigo, revisito as artic ulações do erótico na versã o de Freyre do sujeito nacional brasileiro. Mapeio c omo o erotismo produz uma figura ra cial, o mestiç o, cuja partic ula ridade reside em ser um objeto esc atológ ic 0 , isto é, uma figura histórica destinada a desaparecer. Enquanto essa figura tem sido celebrada como o símbolo produtivo e unificador da brasilidade, tem efeitos materia is opostos. Como dispositivo polític o/simbólic o, o mestiç o institui sujeitos soc ia is suba lternos. Isso é conseqüência de como a miscigenação, como signific ante históric 0 , antec ipa a oblitera ção (físic a e simbólic a) de negrose índios. Isso é resultado, como mostro, da construção da mulher não branca como um instrumento (não como objeto) do desejo colonial. Como tal, isso também está pressuposto dentro dos mecanismos do sujeito racial que prevalece no Brasil contemporâneo.
\end{abstract}

Palavras-chave: erotismo, sexualidade, miscigena ção, Brasil, patria rcado.

Copyright () 2006 by Revista Estudos Feministas

\section{Introdução}

\begin{abstract}
Penso que a história teria teminado se a disparidade de direitos e padrões de vida fosse reduzida: esta teria sido a pré-condição de um modo de existência a-histórico, do qual a atividade erótica é sua forma expressiva. Desde este ponto de vista necessariamente hipotético, a consciência da verdade erótica antecipa o final da história; esta consciência traz profunda indiferença ao tempo presente, a "apatia" de um julgamento a-histórico, de um julgamento a tado a perspectivas que são muito diferentes daquelas de homens totalmente engajados em lutas.

George Bataille, A parte maldita (The Accursed Share)

Por que se pode conceber o discurso como produtor de diferença sexual, mas, apesar disso, aceitar que as diferenças físicas são o referente "material" da diferença racial? 0 que acontece com os aspectos sexuais e raciais como qualificadores da diferença humana que concedem a estesum objeto menos a tra ente
\end{abstract}


${ }^{1}$ Ao distinguir, em sua História da sexualidade, entre "uma simbologia do sangue" e a "análise da sexualidade" - na medida em que posiciona essa simbologia no arranjo epistemológico no qual o corpo constituiu a superfície da signific ação da autorida de do re -, Michel FOUCAULT, 1978, faz mais que ensaiar o banimento moral do conceito de raça do período pós-Segunda Guerra Mundial. 0 que sua afirmação a mbígua, que reconhece a operação da "simbologia do sangue" no Nazismo e no aparato da biopolítica, faz é refigurar a pobreza analític a que resulta de que nem as "pós"-críticas do pensamento moderno, nem a teoria racial crític a esta belecem - racial para guiar seus desafios a visões onto-epistemológicas modemas. Não é de surpreende que as apropriações da noção de Foucault de poder produtivo, ta is como a de Judith BUTLER, 1993, vinculariam muito as críticas de considerações existentes de sujeição de gênero que se apóiam em uma visão natura lizada da diferença sexual, enqua nto novas considerações crític as de sujeição racial - tais como em Michael OMI e Howard WINANT, 1994 - conservariam a diferença racial como um a tributo natural, divino. Para uma elaboração dessa crítica da visão predominante da sujeição racial, ver Denise SILVA, 2001 2005, e no prelo.

2 Para uma já clássica crítica da suposição de que a transparência é o atributo distintivo do sujeito modemo, ver Gayatri SPIVAK, 1994.

${ }^{3}$ FREYRE, 1987. do desejo crític $0 ?^{1}$ Neste a rtigo introduzo a disc ussã o sobre o modo de operação do aspecto racial e sexual como estra tégias polític as simbólic as - mecanismos de sujeição social - que focalizam como o desdobramento do erótico na esc rita do sujeito (nacional) brasileiro, o mestiço, institui um sujeito moderno, cuja trajetória temporal é um movimento em direção ao auto-apagamento. Mostrando como a versão hegemônic a da especificidade, da democracia racial, do aspecto racial e sexual se combina m na escrita de um sujeito social subaltemo, essa leitura de uma imagem pós-colonial do mestiço também mostra como a miscigenação, como ferramenta de análise de racialidade, opera como estratégia política/simbólica da sujeição racial.

A estruturação desse exercício de a nálise crítica mapeia conc eitua Imente o sujeito do Pós-lluminismo, o "eu" transparente, que centraliza sobre as a rticulações o histórico, o sexual e o racial para escrevê-lo como um produto e instrumento da razão universal. ${ }^{2} 0$ que 0 movimento analítico que desenvolvo aqui faz é mostrar como, na escrita de Gilberto Freyre $^{3}$ sobre a especific ida de brasileira, o sexual e o racial, como significantes de regulação - científicos e mora is (patriarcais), respec tiva mente -, produzem a trajetória temporal do sujeito brasileiro (nacional) como um movimento dual de apagamento de "índios" e "africanos" e a autoprodução do europeu. Isto é, essa escrita introduz uma articulação de um "eu" transparente (histórico), no qual tanto as ferramentas da sociologia das relações de raça quanto da antropologia do século XX produzem o sujeito nacional privilegia do (branco/português), e o sujeito social subaltemo mestiço que, por incorporar os atributos de "desa parecimento" do aspecto racial e cultural do "Outro europeu", emerge como o sujeito de um desejo destrutivo, o a gente de sua própria a niquilação. Resumindo, a versã o de Freyre sobre a democracia racial exemplifica como as na rra tivas da nação ta mbém desenvolvem os meca nismos polític os/simbólic os da sujeição social.

Minha leitura mostra como Freyre articula o erótico em um texto nacional, no qual o fato da miscigenação representa um papel crucial em sua escrita de um sujeito nacional como efeito da regulação tradicional (moral/ patria rcal) - um movimento engenhoso, pois o patria rc a do continuou sendo uma descrição a utorizada do sujeito modemo na medida em que estivesse restrito ao domínio da vida doméstica (privada). Além disso, ta mbém permite a construção da miscig ena ção como um descritor positivo da configuração social bra sileira modema a penas porque o exc esso que ela produz, o perigoso fruto da relação sexual 
entre senhorese escravas, pode serentendid o como sobra. Isto é, meu a rgumento é que, enquanto o produto do desejo português, o mestiç 0 , se torna o símbolo da especificicidade do Brasil, sendo uma figura fundamenta Imente instá vel, pois é uma incorporação temporária da brasilidade, um passo necessário para sua expressão real, o sujeito brasileiro é sempre já branco, pois Freyre, assim como outros antes dele, constrói o português como o sujeito verdadeiro da história brasileira. Portrás desse texto está uma preoc upação com as conseqüências dessa representação de brasilidade, mais especialmente com as escritas a tua is sobre violência urbana, que, penso, são a materia lização espera da de uma na rrativa hegemônica nacional, que está fundamentada no desaparecimento do mestiço, o sujeito social que é, primeiramente e principalmente, o produto de um desejo destrutivo. Como tal, essa visão da sujeição racial no Brasil tanto parte das rejeições apressadas da democracia racial que descreve, quanto de um subterfúg io - isto é, um mascaramento da supremacia branca. Pois estou convencida de que essas escritas reposicionam o sujeito social bra sileiro, o ma is ou menos mestiç 0 , bra sileiro ec onomic a mente despossuído, so litá rio dia nte do horizonte da morte, quando afirmam que, por não conseguirem reconhecer sua diferença racial, não podem mudar suas condições. Assim, reproduzem o mestiço como o único responsável pela sc irc unstância sque leva m a essa perigosa situa ção social, que a gora, ma is do que nunca, ma is do que sob a escravatura, está marcada porepisódios de "total violência" - isto é, o controle alta mente orga niza do e brutal que o narcotráfico tem sobre as favelas e periferias no Rio de J aneiro e outros centro urbanos.

\section{Escritas do desejo}

É certo que a vida erótica não pode ser regulada [réglé] Foram dadas regras, mas estas regras a penas conseguiram a tribuir a ela um domínio fora das regras. E uma vez que o erotismo estava descartado do casamento, este tendia a pressupor um aspec to material primordial, cuja importância Lévi-Strauss estava correto em enfatizar: as regras assegurando a troca de mulheres como objetos desejados de fato asseguraram a troca de mulheres como forca de trabalho.

- George Bataille, A parte maldita (The Accursed Share)

Meu movimento neste texto é ler o mestiço como uma figura pós-colonial, que vejo como uma contribuição a uma teorização pós-colonial da relação entre a miscigenação (hibridismo ou mistura racial) e processos contemporâneos de sujeição racial. Pois, se a figura ontológica pós-lluminismo dominante, o sujeito, é to talmente autodeterminado, uma coisa autoproduzida 
${ }^{4} \mathrm{O}$ sujeito nacional, o construto que dá a precisão da dimensão histórica (moral) dessa figura, ocuparia um lugar privilegiado nas últimas décadas do século XIX, como discutem Benedic ANDERSON, 1983, Eric HOBSBAWN, 1994, e outros.

${ }^{5}$ VerSILVA, 2001, e no prelo, para uma crítica da lógica da exclusão.

${ }^{6}$ YOUNG, 1995.

\begin{abstract}
7 "Muitos romances do passa do", ele discute, "exteriorizaram ta is inseguranças e diferenças e estão preocupados com encontro e incorporação da cultura do outro, seja de classe, etnic ida de, ou sexua lida de; eles sempre fantasiam cruzá-la" (YOUNG, 1995, p. 3)

8 "Lingua gem e sexo", ele alega "constituem os predominantes loci de compromisso com essa afirmação de formas 'híbridas' igualmente produzidas", que "foram vistas como incorporação de formas ameaçadoras de perversão e degeneração e tornaram-se a base de uma extensão metafórica sem fim no discurso racial do comentário social" (YOUNG, 1995, p. 4).
\end{abstract}

${ }^{9}$ YOUNG, 1995, p.108. (moral/histórica) e auto-reguladora (jurídica), ${ }^{4}$ como ler a trajetória de um tipo particular de sujeito moral, um sujeito nacional (histórico), que parece renunciar à autodetermina ção, para "abraçar" sua a meaça a os "outros"? Ao atentar para essa questão, parto da visão predomina nte do papel do mestiço, que o constrói ou como o significante de fantasias que serviu muito bem à dominação colonial, ou como a refiguração de um processo de exclusão fracassado. Isso, acho, resulta da permeabilidade da lógica de exclusão - como a versão privilegiada da sujeição racial - e da suposição de que a diferença racialé um a tributo humano (pré-conceitual/préhistó rico $)^{5}$ importante. Diferentemente, começo da suposição de que a diferença racialé produto de a paratos c ientífic os estabelecidos para explicar uma varieda de de configurações huma nas corpóreas e socia is encontra das nas vá rias regiões globa is.

Em Desejo colonial (Colonial Desire), por exemplo, Robert Young 6 desafia posições "neo-racistas" de inglesidade como uma "identida de fixa", mostrando como uma "necessidade de alteridade" - uma obsessão em relação a "cruzamentose inva são de identida des" - marca os escritos da identidade inglesa do século XIX. ${ }^{7}$ Essa "ansiedade" com o cruzamento, argumenta, é um efeito de projetos coloniais e imperia is que envolvem um maior movimento de pessoas e cultura que, para os europeus, tomou a aparência de "ruptura da cultura doméstica, e um aumento de ansiedade em relação à diferença racial e ao amálgama racial que era aparente como um efeito do colonia lismo e da imigração compulsória". ${ }^{8}$ Descreve o colonialismo como uma 'máquina de administração de guerra desejante' cujas "conexões e disjunções" forçadas de territórios, histórias e povos também produziram sua "própria fantasia mais escura", as abundantes uniões sexua is (inter-racia is) 'nã o-natura is'. "O corolário deste [desejo do homem branco]", ele debate,

é que a a dulteração da raça deriva da a tração sentida pelo branco em relação ao negro ou ao amarelo e, portanto, por inferência, já que a produção de filhos misturados é o tema, pelo homem branco em relação à mulher amarela ou negra [...]. Quanto ao poder hierárquico, a resposta do homem branco ao apelo da exótica sexualidade negra é identificada com a posse e a dominação, sem dúvida alimentada pela resistência da mulher negra. Este imperativo sádico, aumentado pela repugnância sentida pelo negro ao branco, está inevitavelmente acompanhado pelo requisito de submissão masoquista da mulher subord ina da, objetific a da. ${ }^{9}$ 
Sem dúvida, o mapeamento de Young da economia erótica colonial da atração e repulsão adiciona uma dimensão crucial, a sexual, a os momentos econômicos e jurídicos do poder colonial.

No entanto, enquanto tal abordagem apreende dimensões importantes dos escritos colonia is do final do século XIX, não creio que se aplique imediatamente a escritos pós-coloniais dos "outros da Europa", pois as construções do século $X X$ da especificidade européia já encontraram uma reserva de formulações científicas do racial, do culturale do sexual, que osproduzem como efe ito de um tipo característic o de regulação, a saber, as "leis da natureza", que produzem categoria sinegá veis e irredutíveis de seres humanos. 0 que quero dizeré: qua isquer a ná lises críticas de como as representações de miscigenação operam como mecanismos de sujeição racial deveriam incluir um mapeamento das articulações existentes do sujeito moderno como um objeto desejante, ou seja, como um efeito da regulação (juńdic a, científic a ou moral) e como um efeito da representação (histórica). Farei isso em três movimentos. Primeiro, faço brevemente a distinção entre duas articulações do desejo, a histórica, a escrita inicial de Hegel do sujeito a uto-rep resenta do (a utodeterminada), e a psicanalítica, a visão de Freud do sujeito sexual como um efeito da regulação científica e moral. Segundo, ta mbém descrevo brevemente como, quando emprega o racial e o cultural como significantes de uma regulação científica, a analítica da racialidade produz uma versão do sujeito que se afasta radicalmente da visão única ontoe pistemológica pós-lluminista. Finalmente, retomo brevemente a reescrita de Bataille sobre o sexual a lém da regulação, a lém do casamento e da reprodução, para mapear sua própria a rtic ula ção do sujeito como uma coisa consumidora. Esses movimentos g uia rão minha a nálise dos efeitos da articulação do erótico no ma is antigo texto regulado pela representação históric a do sujeito como coisa/objeto do desejo, ou seja, a versão de Freyre do texto b rasileiro.

\section{0 histórico}

A definição cartesiana do sujeito, figura central da representação moderna, estabelece uma conexão fundamental entre o objeto autodeterminado, o sujeito e a certeza no conhecimento. Enquanto o regente e o autor divinos sustenta ra m a s visõ es mora is modemas, a confiança do sujeito no conhecimento não foi um problema. Porvolta do fim do século XVIII, depois da mudança epistemológica ma rca da pelo lluminismo, pela mudança política indicada 
${ }^{10}$ HEGEL, 1977.

pela revolução americana e pelo momento econômico instalado pela revolução industrial, somente a razão universal forneceria a base para uma visão da especificida de humana. Embora do ponto de vista jurídico, econômic o e científico a consolidação da razão universal como um princípio seria bem-vinda como um conforto tardio, o deslocamento do religioso deixaria uma lacuna de valores morais. Como explicar o contrato social? Como justificar laços humanos que não estão reduzidos ao interesse próprio, à necessidade de acumulação, sem recorrer a um significante religioso - de um primeiro exemplo, como Herder descreve a autoridade divina, que permaneceria então como o princípio que guia ria as vidas das pessoas na medida em que realizavam a tempo suas potencialidades e possibilida des coletivas e únicas? Ma is importante, como poderia a razão universal, que a té aquele momento havia sido considera da uma força limita nte - nas instâncias c ientífic a s e juríd ic as - encontra r um va lor moral que não partisse da escrita inicial do sujeito na a utodeterminação como um objeto de liberdade?

Ao ocupar-se dessas questões, em seu Fenomenologia do espírito (Phenomenology of Spirit), G. W. F. Hegel ${ }^{10}$ reescreve a razão universal como a força soberana autodeterminada (autoproducente e autoreguladora), cujas habilidades são postas em prática na configuração social (jurídica, econômica e moral) da Europa pós-lluminismo. Com isso, ele consolida histo ric ida de como o horizonte ontológ ic o no qual o sujeito emerge como um objeto transparente (interior/temporal). Seu movimento é descrever a trajetória da consciência, o movimento dialético da razão universal - que ele renomeia como "Espírito" - como atividade a utoprodutora e autorepresenta tiva. Atra vés dessa refiguraçã o da razão universal, que marca sua consolidação como a regra soberana dos valoresepistemológicosmodemos, Hegel a reescreve como aquela que abriga todas as possibilidades e potencialidades que ela desdobra e recupera no tempo, um Sujeito Transcendental que é fundamentalmente um objeto interior/temporal. Para Hegel, a verdade da autoconsciência é

$$
\begin{aligned}
& \text { a unidade da autoconsciência consigo mesma; esta } \\
& \text { unidade deve tornar-se essencial para a } \\
& \text { autoconsciência, isto é, autoconsciência é Desejo em } \\
& \text { geral. A consciência, assim como a autoconsciência, } \\
& \text { daqui em diante, tem um duplo objeto: um é o objeto } \\
& \text { imediato, aquele da certeza do sentido e da percepção } \\
& \text { que, para a autoconsciência, no entanto, temo caráter } \\
& \text { de uma negativa; e o segundo, o próprio ser (itself), } \\
& \text { que é a verdadeira essência, e está presente na }
\end{aligned}
$$


${ }^{11}$ HEG EL, 1977, p.105. Itálic os no original.
12 HABERMAS, 1987. primeira instância apenas em oposição ao primeiro objeto. Nessa esfera, a a utoconsciência exibe-se como o movimento no qual essa antítese é removida, e a identidade do ser consigo mesmo se toma explíc ita. ${ }^{11}$

Na interpretação de Hegel, a realização do sujeito como um objeto a uto determina do requerum envolvimento tanto com a essência 'abstrata' quanto com a existência 'concreta' dos objetos (coisas e outros "eus"), pois a mbas precisam estar engajadas para a rea liza ção da trajetória da autoconsciência em direção à Liberdade (a utodetermina ção). Isso ocorre quando a autoconsciênc ia a dquire "universalidade verdadeira", a o completar-se sua trajetória - depois que recupera a morte, negação, como uma dimensão do próprio ser (itself) -, autoconsciência como "ser para si mesma", isto é, o momento da tra nspa rência. Os rela tos histó ric os posteriores da especific ida de huma na assumirão a formula ção de Hegel, que institui o sujeito como um "eu" transparente. Na a ríc ula ção históric a do sujeito como um objeto desejante, o outro como o momento da morte, já está definido como um aspec to da autoprodução do sujeito. No entanto, este outro também está articulado como aquele sem o qual a transcendência, a transparência da morte (o "outro", o objeto)não pode sera lc ançada. Pa ra resumir, a a rtic ula ção histórica do sujeito como objeto desejante - aquela que finalmente reconcilia o jurídico e o moral e, como afirma Habermas, ${ }^{12}$ fomeceu à modernidade um fundamento cultural (moral) - resolve o perigo que a alteridade anuncia como um momento necessá rio e produtivo da trajetória temporal (histórica) da autoconsciência, de sua compreensão como uma coisa moral. O sucesso de Hegel foi consolidara historicidade como o horizonte ontológico privilegiado, aquele pressuposto pelos relatos ontoepistemológic os do pós-lluminismo e no princípio moral que descreve o sujeito (autoconsciente) como um objeto desejante.

\section{O sexual}

$\mathrm{Na}$ descrição psicanalítica do sujeito do desejo, encontro uma inversão que descreve a emergência do sujeito social (civilizado) como um objeto desejante, não como uma manifestação da autoprodutividade humana, de liberdade, mas de necessida de - tanto de instintos como das regras (tradições socia is e costumes) que a família heterossexual estabelece e incorpora - que distingue o humano de outros animais. Em seu Compêndio de psic a nálise (Outline of Psychoanalysis), ${ }^{13}$ Sigmund Freud faz um resumo do arsenal conceitual que guia sua 
${ }^{14}$ FREUD, 1940, p. 158.

${ }^{15}$ SILVA, 2001, e no prelo. reformulação científic a do estudo da psique humana, que começou com sua declaração sobre a existência de determina ntes inc onsc ientes d os proc essos consc ientes. "Os processos com os qua is se preocupa [a psicanálise]", a firma,

são em si mesmos tão indesc ritíveis quanto a queles com que lidam outras ciências, a química e a física, por exemplo; mas é possível estabelecer as leis que obedecem e seguir suas relações mútuas e interdependências... - resumindo, chegar ao que é descrito como uma 'compreensão' do campo do fenômeno natural em questão. ${ }^{14}$

Ademais, além de ser um efeito das "leis da natureza", cuja operação a psic a nálise ma peia, de acordo com Freud, a economia psíquica humana também reflete as operações das regras socia is (exteriores) - através de confirmação do superego sobre o id (instintos), crucial no desenvolvimento do ego - que os pais representam e reforçam. "Esta influência parental", diz, "inclui em sua operação não somente as personalidades dos pais, mas ta mbém a família, tra dições racia is e nacionais passadas através deles, assim como as demandas do meio social imediato que eles representam". Aqui encontramos uma articulação do social como um domínio de regulagem distinto do de Locke, em que as suas leis são efeitos do consentimento, enquanto na psicanálise, como em outros escritos científic os sobre o humano, a regulação produzo sujeito social porque é a condição de possibilidade para sua emergência como tal. O que distingue as articulações históricas e sexuais do desejo? Entre elas, creio, está uma transforma ção onto-epistemológica que os escritos de Hegel sobre o sujeito como um objeto desejante tanto permitiram quanto exigiram. Para a reescrita de Freud, o desejo é um aspecto do indivíduo como um objeto moral, isto é, as regras que instituem o indivíduo como sexual não operam em nível legal - como as leis da sociedade - mas em um domínio jurídico que as precede e também é regulada porelas.

\section{0 racial \& o cultural}

Muito próximos à psicanálise, os projetos científic os - a Ciência do Homem, a sociologia dasrelações de raça, e a antropologia do século XX - que, a partir do século $X I X$, escreveriam configurações corpora is e socia is enc ontra das nas vá rias regiões do g lobo como signific a ntes de diferentes tipos de mentes humanas, também introduziram uma visão de consciência como um efeito da regulagem científica. Em outros artigos, ${ }^{15}$ mapeio esses 
lugares de produção do racial e do cultural como significantes da diferença mental (moral e intelectual). 0 que farei a seguir é resumir esse argumento, descrevendo os tipos de sujeitos que esses luga res produzem.

o que diferencia os relatos da diferença humana informados por essas estra té gias políticas/simbólicas, a rgumento, é que não pressupõem a historicidade como o único horizonte ontológico. Ao invés disso, as representações científicas do racial e do cultural pressupõem um horizonte ontológico, globalidade, que não pode ser reduzido, diluído, em a utoprodutivida de, pois isso não pressupõe a utodeterminação. Como uma ferramenta política/simbólic a que refigura a espacialidade, diferença irredutível, entre os habitantes da Europa e aqueles de outros continentes, o racial produz sujeitos modemos como objetos funda menta Imente exteriores, como a utoconsciência sque permanecem fixadas naquele momento que Hegel descreve no trecho do senhor/escravo, que se engaja na luta de vida e morte antes de a escravidão transforma $\mathrm{o}$ perdedornuma ferramenta, num instrumento, do vencedor. Como objetos raciais, os sujeitos modemos, a firmo, olham com horror o horizonte inapreensível da morte. Este artigo é guia do pordo is movimentos a na lític os. Em primeiro lugar, essa abordagem da escrita sobre o mestiço emprega a racia lida de como uma estra tég ia de signific a ção c ientífica, como uma ferramenta política/simbólica, cujo papel primordial é produzir config urações socia is modemas, em que institui as regiões mora is habitadas pelos: a) sujeitos transparentes (autodeterminados) da vida - brancos/ europeus - que incorporam o vencedorna visão de Hegel da luta de vida e morte, os que alegremente dividem as vantagens da vida ética, a queles cuja existência social é regulada pela universalidade e autodeterminação princípios que governam as dimensões econômica e jurídic a; e b) os sujeitos vulnerá veis da morte (determina dos pelo exterior) - os "outros da Europa" -, a queles oblitera dos na luta que condensa o momento da exterioridade, a queles para quem os princípios que distinguem as configurações socia is modemas não se aplicam, aqueles que não são nem o sujeito legal pressuposto pelo aparelho jurídico execução da lei e a dministração da justiça - nem o sujeito a tendido pelas políticas públicas.

Minha leitura dos efeitos do erótico, quando empregados na representação de Freyre do sujeito brasileiro, que é governada pela articulação histórica do sujeito, mostrará como esse uso do arsenal da a nalític a da ra cialida de constrói o mestiço como um símb olo do sujeito da morte. Isso, como mostro, resulta de um emprego da atividade erótica que, por presumir um soberano (sujeito 
absoluto do desejo), o português, não antecipa o desejo do "outro" feminino, que, a qui, emerge como um objeto o material cru e instrumento que, como tal, nã o apresenta a mea ça à sua a utonomia. Pois, não tendo nenhum a tra tivo para si a lém de sua disponibilidade a utoriza da (legal), como fêmea e como escrava, ela é a "morta-fixa", que o mestiço efetiva uma vezque incorpora seu apagamento, o uso de seu corpo africano, necessário para a construção da configuração social modema (jurídico-econômica, moral) fora do continente europeu, nas terras tropica is onde os primeiros articula dores de racialidade, os cientistas do homem do século XIX, disseram que nunca prosperaria. Em resumo, a eficiência da racialidade como estratégia política/simbólica modema reside no fato de seu arsenal de racia lida de reconcilia ros valorescientífic osa os históric os da diferença humana porque esc reve os "outros da Europa" como sujeitos vulnerá veis, como aqueles cujo destino não é a transparência, maso apagamento.

\section{Desejo patriarcal}

$$
\begin{array}{r}
\text { Digamos que o desejo sempre busca dois objetos, um que é } \\
\text { móvel e vivo, outro que é fixo e morto. E o que caracteriza o } \\
\text { erotismo não é o vivente-móvel, mas o morto-fixo que, } \\
\text { sozinho, é separado do mundo normal. Este é o fim para o } \\
\text { qual queremos levaro vivente-móvel. É questão de se } \\
\text { quebrarem as seqüências comuns e conscientes de forma a } \\
\text { encontrar o que foi separado: o que foi separado existe } \\
\text { a penas como um objeto ou como uma fusão. } \\
\text { - George Bataille, A parte maldita (The Accursed Share) }
\end{array}
$$

Se a representa ção psic ana lític a do objeto desejante nega essa essência, liberda de, pa ra instituiro sujeito modemo como um objeto social, como um efeito de uma regulação pré-simbólic a, qual seria o efeito da a rticulação do erótico na escrita de um sujeito modemo, um objeto moral? Como o erótic o produz um sujeito histórico, um ser cuja trajetória é um retomo à transparência, a superação da 'universalida de simples', a universalidade da regulação (divina e jurídica) que acontece apenas quando comprometida com a exterioridade, a autoconsciência percebe que sempre já é ela mesma, que a regulagem não é necessária, pois um vínculo fundamenta la liga com aquilo que não é ela mesma; que o episódio da luta pela vida, no trecho senhor/escravo, no qual a violência, a possibilidade da morte, marca sua relação com uma outra autoconsciência, nunca seria repetido, pois alcançou a "vida ética"?

Para lidar com essa abrangente questão, cuja resposta demandaria uma visão de cada articulação do sexual nos esc ritos dos sujeito s históric os e na ciona is, revisito um texto histórico no qual o erótico representa um papel 
${ }^{16}$ BATAILE, 1993.

${ }^{17}$ Não vou me envolver em uma crítica da apropriação de Bataille da tese de Lévi-Strauss de que o tabu do incesto é produto do social, e de que a circulação de mulheres produz alianças que permitem a existência social.

${ }^{18}$ BATAILLE, 1993, p. 48. crucial na produção de um sujeito histórico. Ao fazer isso, ta mbém indico como a versão de Freyre é informada pelas estra tégias signific a ntes científic as - A Ciência do Homem, a antropologia do século XX (Antropologia) e a sociologia das relações de raça (Relações de Raça) - que constituem a a na lític a da racialidade. Esse a pa relho político/simbólic 0 , institui o racial como uma ferramenta onto-epistemológ ica, aquela que institui o sujeito como um objeto global (exterior) espacial), que sempre já pressupõe a violência, pois emerge ao lado e diante de um outro cuja existência o horizonte ontológ ico privilegia do, a historicida de, nã o pode levar em conta, pois pressupõe que a emergência do próprio sujeito está baseada na redução/negação de tudo que é interior a ela. Antes de desc revercomo Freyre constrói o mestiço como um sujeito sempre já em movimento em direção a o horizonte da morte, volto a uma discussão do ponto de vista de Bataille sobre o erotismo, que ajudará a mostrarcomo ele esc reve o desejo irreprimido do português como uma força produtiva que é leva da pela necessidade de consumir aquilo que é necessário para demarcar sua particula ridade.

\section{A crítica da produtividade regulada}

O que vejo na escrita de Georges Bataille sobre a atividade erótica em seu A parte maldita (The Accursed Share) ${ }^{16}$ é tanto uma crítica e uma re-articulação da construção do sujeito quanto um efeito da regulação social (jurídica e moral). ${ }^{17}$ Para Bataille - assim como para Locke e Hobbes, os estruturadores da regulação jurídica - a emergência do humano ocorre no a to radical da separação do a nimal. É um efeito de uma aversão à natureza como aquela que é dada aos seres humanos que é, a o mesmo tempo, o estabelecimento de regras e o início da história. Dessa ruptura, Bataille a rgumenta, emergem os dois qua lifica dores exc lusiva mente humanos - o racional, que ele associa à lógica da aquisição da produção material, e o erótico, que ele coloca como o oposto, a saber, a lógica excessiva do consumo sexual. Para ele, no entanto, não tanto as regras, mas o estabelecimento de regras mais sua transgressão distinguem a sexualidade humana. A "formação do erotismo", discute, "implica uma altemância de repulsão e a tração, de negação e de afirmação, uma alternância imediata em que é humano (erótico) e não simplesmente sexual a nimal". ${ }^{18}$ Pois o erótico institui o humano a tra vés da oposição entre as regras produtivas (da história e da economia) e a transgressão, o retorno à animalidade rejeitada que deriva seu poder precisamente do fato de 
que é um rompimento com a regulação produtiva. Na atividade erótica, o consumo não está submetido à produção regulada - que é levada tanto pela infinita abundância de vida quanto pelo vazio anunciado pela morte. Isto é, ele critica a produtividade econômica, a lógic a utilitária da regulação na qual a produção é a justa da em direção à maximização do resultado com a menor despesa possível de recursos disponíveis.

De qualquer forma, o relato de Bataille sobre o erótico indica mais cla ramente a diferença entre essas duas a rtic ula ções do sujeito como um objeto desejante, a saber: (a) histórica, a quela que submete a regulação à autoprodução; e (b) a sexual, a quela que reduz a a utoprodução à regulação daquele aspecto da particularidade humana que concebe o consumo como um momento de produção, aquele que reduz a vida a uma atividade produtiva sempre ajustada em direção à sua própria prevalência - aquele, em resumo, que não pode produzir a morte, a negação de assumir qualquer papel na determinação de ser/vira ser. Exatamente porque o erótico desafia e ignora esse privilégio de tomar-se e anuncia a concepção de vida como aquela que é produtividade não-regulada, que não apenas retoma à animalidade, mas também abraça a morte como uma possibilidade capacitante, não ca i nem na a rticulação do desejo hegeliana nem na freudiana. Para Bataille, o outro, o objeto do desejo sexual, não pode ser reduzido nem à regra histórica, nem à patriarcal, pois só existe como uma rejeição a ambas. Como tal, o erótico é o máximo significante de liberdade. Não a penasnão marca uma volta para a animalidade, um retorno à natureza sem a mediação das regras que a a rrancam dela, como ta mbém a pena sexiste porseruma tra nsg ressão das regras, a s regras que definem a humanidade. Nem um efeito da nec essidade (como a natureza o concebe), nem um objeto de regulação (apropriação da natureza pelospróprios seres humanos), o erótic 0 , na representa ção de Bataille, significa humanidade e aquilo que a especifica, a vida, sem regulação. Mesmo assim, precisamente porque não pode estar sem regulação, o erótico já a nuncia como esta regulação que institui o ser humano, como ela inscreve o ser humano não como efeito de qualquer tipo de regula ção, mas a quela cuja s ontologia s modema s tiveram de negar quando o divino foi deslocado para assunção das onto-epistemologias humanas.

Ao discutir a crítica de Bataille da regulação, em minha leitura da democracia racial, focalizo como, na versão de Freyre do contexto colonial brasileiro (jurídico, econômic o e moral), uma instância particularde regulação 
- a significação científica - permite uma a propriação do erótico como a expressão do desejo que segue a lógica da produção em que o excesso não é um significante da efusão que carateriza a produção não-regulada (apenas por ser transgressora). Isto é, minha tarefa é mostrar como, na narrativa do sujeito brasileiro, o retomo ao rejeitado/ abjeto, a transgressão das regras - do intercurso sexual, do consumo produtivo, do casamento - da humanidade, a a rticulação simultânea do racial e do sexual produzem tanto um sujeito na cional que é um sujeito históric o de poesis quanto um sujeito de abjeção, isto é, aquele cuja única trajetória é o gasto, cujo destino é o apagamento. O que discuto é o efeito do excesso, a articulação de Freyre dos luga res erótic os no âmago da na rrativa do sujeito brasileiro.

\section{Luxúria produtiva}

Nesta leitura da versão de Gilberto Freyre do sujeito brasileiro, vejo sua escrita contraditória de um sujeito modemo (nacional) como um "eu" tradicional (patriarcal), como um efeito do uso das ferramentas da Antropologia e das Relações de Raça que, porvolta de 1930, constituíram os relatos científicos autorizados da diferença racial e cultural. O emprego dessas significativas estratégias c ientífic as tem do is efeitos primá rios. Por um la do, o a rsenal da sociologia das relações racia is permitiu uma na rrativa que mostra que, desde suas "origens", o sujeito brasileiro exibiu os a tributos necessários para construir uma "civilização modema" nos trópicos, ou seja, a habilidade de "assimilar" as "culturas e raças inferiores", preencher o "ciclo de relações de raça". Por outro lado, tanto a escrita antropológica do "nativo" como sempre já "desaparecendo" quanto a afirmação das relações de raça da sociologia de que a miscigena ção constitui a única solução do "problema de relações raciais" apoiariam a tese de que o Brasil é uma democracia racial exatamente devido à falta de "preconceito racial" dosportugueses, que resultou no rápido desaparecimento de índios e africanos vulnerá veis do Brasil. Enqua nto índios, a frica nose europeus estão sempre já democraticamente unidos no sujeito nacional transparente, a miscigenação constituiria a "diferença intrínseca" do Brasil, endossando assim a realidade dos brasileiros desesperançadamente miscigenados com uma transparência precária (tropical). Isto é, a miscigenação inscreve com segurança um movimento histórico duplo, a saber, a trajetória teleológica - o movimento em direção à transparência - do sujeito branco/europeu de uma "civilização modema" patria rcal, a trajetória escatológica de seus "outros"; mas, mais 
${ }^{19}$ FREYRE, 1987.

importante, também institui um sujeito social precário, o mestiço - o brasileiro mais ou menos negro ou branco -, cujo destino é realizar um desejo de auto-apagamento.

Em C asa-Grande \& Senzala, Gilberto Freyre ${ }^{19}$ dá uma visão do sujeito brasileiro na qual o patriarcado marca a especificidade brasileira (nacional). Na medida em que ele desc reve como os a tributos ra cia is e cultura is dos "outros da Europa" contribuíram para a especificidade brasileira, ele escreve que a tra jetória temporal do sujeito nacionalé um efeito do desejo português. Seu movimento crucial é escolher o patriarcado, dentre as concepções modemas de autoridade jurídica e relações econômicas, para fazer da "família" e da "vida sexual" lugares privilegiados do emprego do desejo do português (masculino). Por consid erar o escravo a dulto, o traba lhador dos la tifúndios, absolutamente irrelevante no rela to da história brasileira e, conseqüentemente, enfatizar a posição privilegiada do colonizador europeu branco, para Freyre, somente a escrava representaria o "outro da Europa" que ajudou na produção daquilo que marca a "diferença intrínseca" brasileira, a saber, o mestiço. Dessa forma, Freyre escreve os "outros da Europa" como duas vezes vulnerá veis: não a penas a escrava é juńdica e ec onomica mente subjuga da, mas a sua é uma forma particular de sujeição de gênero, pois, numa configuração patria rcal/escravista, a família constitui o centro das concepções prevalecentes de moralidade. Aqui a diferença racial não tem nenhuma função na configuração jurídica, econômica e moral do Brasil colonial. Ao contrário, está determinada na interioridade do sujeito "levemente bronzeado" do patria rc a do. Não surpreende que a lógica da exc lusão não possa capturaro modo da sujeição racial que esse rela to a utoriza, pois assume que a miscigenação, como um processo e como indicador da obliteração da diferença racial, institui configurações sociais em que o racial não opera como estratégia de poder.

o que leio na versão de Freyre sobre o sujeito brasileiro é uma descrição da produção de dois tipos de sujeito: o sujeito históric o, o português, cuja falta de preconceito racial permite a construção da "civilização moderna" em terras tropicais, inóspitas; e um sujeito social (um produto da regulação jurídico-econômica ), o mestiço, que resulta de dois momentos de violência autorizada, o uso econômico dos corpos dos escravos como má quinas produtivase a a propriação do corpo da escrava não como um sujeito erótico, mas como um objeto, como uma bananeira ou uma ovelha, que produziria o tipo de corpo a dequado para a tarefa de construir uma civilização tropical. Precisamente porque a figura soberana jurídica

74 Estudos Feministas, Florianópolis, 14(1): 61-83, janeiro-a bril/2006 
da casa-grande é aquela à qual Freyre atribui as c a rac terístic as que marcam a espec ific ida de moral do Bra sil - adaptabilidade, miscibilidade e falta de preconceito ra cial, o sujeito brasileiro herda a penaso corpo, mas nada do espírito africano da escrava, instrumento que o senhor da casa-grande usa na produção do sujeito social - o trabalhador, o concreto, em oposição ao abstrato, o ma terial em o posição a o construtor esp iritual da civiliza çã o brasileira. Ele é o resultado da violência produtiva (autorizada). É total e exc lusiva mente o exterior, o social, a incorporação de um desejo que se realiza na violência autorizada, a apropriação, uso e abuso dos corpos de escravos e escravas cujo único papel é assegurar que se reproduzam sem nunca submeter-se aos comandos da natureza, a quilo de que se precisa para a reprodução física, comida e sexo.

No entanto, grande parte do texto de Freyre é dedicada a um relato da influência do "escravo negro na vida sexual e fa miliarbrasileira". É a qui que a representa ção de Freyre da interpretação antropológica da diferença cultural para escrever o sujeito brasileiro como um sujeito tradicional (patriarcal) de uma democracia está condicionada à articulação dos "outros da Europa" em vulnerabilidade que estabelece uma versão histórica de seu necessário a pagamento. O que essa centralida de da família patriarcal permite é o deslocamento imediato do escravo adulto, o que é abarcado por referências gerais a o "Negro" ou ao escravo, mas virtualmente nunca entra no texto em relatos do trabalho duro nos latifúndios.

Na suavida de, na mímic a excessiva, no ca tolic ismo no qual divertimos nossos sentidos, na música, na caminhada, na fala, nas canções de ninar para o menino, em tudo que é uma expressão sincera de vida, trazemos a marca da influência africana: do escravo ou ama que nos segurou, que nos amamentou, que nos a limentou, depois de amaciar a comida em sua boca; da velha negra que nos contou as primeiras histórias de terror; da mulata que nos tratou e que nos inic iou no a mor físic o e nos deu, no ba rulhento colc hão de ar, a primeira sensação de masculinidade; e do menino negro que foi nosso primeiro companheiro. ${ }^{20}$

${ }^{20}$ FREYRE, 1987, p. 283.

Quando recusa o argumento da Ciência do Homem da "inferioridade mental do Negro", na citação inicial, Freyre se refere aos estudos antropológicos contemporâneos da cultura a fricana para reescrever a vulnerabilidade dos negros como um efeito dos processos sócio-históricos. Segundo a lógica da obliteração estabelecida na "teoria dos contatos culturais e raciais" das Relações Raciais, ${ }^{21}$ Freyre descreve como o escravo 
${ }^{21}$ SILVA, no prelo.

22 FREYRE, 1987, p. 357.

${ }^{23}$ FREYRE, 1987, p. 52. afric a no "seria assimila do" dentro da configuração social patria rcal portuguesa.

Em ordem de influência, as forças do sistema escravocrata que agiram sobre o escravo africano recém-chegado são: a igreja, isto é, a pequena igreja da fazenda patriarcal; a senzala; e a própria casagrande - isto é, considerada como parte e não como centro do sistema domina nte brasileiro de coloniza ção e da formação patriarcal. O método de desa fric a nização do 'novo' negro, a seguir, era misturálo com a massa de 'ladinos' ou veteranos, de forma que a senzala tornou-se a escola prática de abrasileira mento. ${ }^{22}$

Embora ele também passe algum tempo enumerando as "influências cultura is a fricana s" não determina ntes - culinária, folc lore, etc. - que o coloniza dor português recebeu de sua a ma negra (escravizada) e seus jovens companheiros negros, para Freyre a única contribuição releva nte dos a fric a nos foi o corpo da escrava.

Além disso, a constituição a ntropoló gic a do conceito do que é cultural, organiza de forma total e consistente, as escritas de Freyre sobre a nação brasileira. Ao descrever as condições coloniais, ele elabora um quadro vivo de uma configuração social tradicional (patriarcal), uma sociedade religiosa, centra da na família, e agrícola, o que constitui a "diferença intrínseca" brasileira. A tra dição conservadora no Brasil", discute,

tem sido sustentada somente pelo sadismo de comando, disfarçado no "princípio de Autoridade" ou na "defesa da Ordem". Entre estes dois mitos- de Ordem e de Liberdade, e de Autoridade e Democracia - nossa vida política, que deixou o regime senhorial e escravocrata cedo dema is, tenta encontrar equilíbrio. De fato, o equilíbrio permanece entre as realidades tradiciona is e profundas: sádicos e masoquistas, senhores e escravos, doutores e iletrados, indivíduos com uma cultura predominantemente européia e outros com uma cultura primariamente indígena e africana. ${ }^{23}$

Em relação à articulação da presença dos "outros da Europa", essa reescrita do dilema da cultura brasileira, que, como vimos anteriormente, é reinterpretada pelas investigações sociológicas, permite tudo a Freyre, menos ignorar os a spec tos vio lentos da coloniza ção e escra va tura, para privilegiarsua influência sobre a família colonial. Com isso, ele reescreve a vulnerabilidade de indígenas e africanos, embrulhando-os no aspecto culinário, afetivo e patológico da vida familiarpatriarcal. Ao descrevero lugar dos indígenas nesse contexto, Freyre rapidamente escreve sua irrelevância, entendendo que sua "preguiça" exigia

76 Estudos Feministas, Florianópolis, 14(1): 61-83, janeiro-a bril/2006 
${ }^{24}$ FREYRE, 1987, p. 159.

uma substituição imediata pelo africano. O que resta do indígena é, a lém dos itens de culinária e folclore, "a parte feminina de sua cultura, que era apenas feminina em sua técnica", porque as mulheres eram responsá veis pelo trabalho de agricultura necessário à "organização econômica agrária que o português estabeleceu nestas terras a meric a nas". ${ }^{24}$

Ao deslocar o contexto jurídico-econômico do colonialismo/esc ravag ismo, a casa-grande patria rc al to mase o microcosmo político no qual a história brasileira se desenvolve. Nesse contexto juríd ic o-econômico, o senhor da casa é soberano, incorpora a própria regulação (jurídica e econômica), como o regente soberano do latifúndio, de sua mulher, filhos, empregados e escravos. Não é meramente um sujeito legal, e não é um sujeito ec onômic 0 , pois outros, mulheres e escravos, são resp onsá veis por sua reprodução, sua descendência, e a reprodução de sua riqueza. Aqui está a primeira indicação de que a estrutura de Bataille do erótico não serve para articular o erótic o no texto nacional brasileiro. Primeiro, nem a religião, nem o Esta do poderiam reivindic ara sujeição do senhorna casagrande, pois no contexto privado jurídico-moral ele é o soberano, uma prerrogativa que os dois Ihe dão. Assim, o casamento, uma das regras que demarcam o campo erótico (como transgressão sexual), é a condição de possibilidade para seu poder absoluto, então não pode reprimi-lo. Segundo, a aversão ao objeto do desejo que compõe a economia erótica por causa da ameaça do retomo à animalidade também não se sustentaria, pois o senhor é duplamente removido de sua natureza. Isto é, a divisão do trabalho reprodutivo e da própria escravatura, que permite que ele fique longe do trabalho - aqui a narrativa de senhor/escravo de Hegel funciona muito bem para descrever -, adia um engajamento imediato com a natureza, uma submissão a seus comandos que a necessidade de a uto-reprodução - procriação e a limentação - exigiria. Finalmente, porque todas as mulheres do latifúndio estão legalmente disponíveis para ele, sua mulher e suas filha s a tra vés do casamento e suas escravas a tra vés da compra, a atração - esse momento do erótic o no qual, mesmo que frágil, o objeto feminino do desejo tem grande importância, pois seu lindo corpo é tão irresistível que o sujeito masculino do desejo arriscará a morte, a quebra das regrasque o constituem como huma no para abraçar esse ser feminino irresistivel - não tem lugar. Ao contrá rio da versão de Bataille, a versão de Freyre sobre o erótico não descreve uma transgressão. Enquanto é, do começo ao fim, possibilitada pela regulação, não é estabelecida como uma quebra de normas, masé possível 
25 BATAILE, 1999.

26 BATAIШE, 1999, p. 84-85.

${ }^{27}$ FREYRE, 1987, p. 371. justamente porque o sujeito do erótico é ta mbém o sujeito soberano das regras. Por essa ra zão, não é um signific ante de produção sem a cumulação, que Bataille ${ }^{25}$ descreve como a atividade prolífica, efusiva, que engaja a morte, 0 dejeto, e o próprio sexo - tudo o que é não-humano, porque está muito próximo do animal - porque concebe a vida como "o movimento tumultuado que explode e se consome... [cuja] explosão perpétua é possível em uma cond ição: que os orga nismos gastos dêem luga ra os novos, que entram na dança com novas forças". ${ }^{26}$ Desde o início, a erótica de Freyre pertence à lógica da reprodução regulada: a primeira regra, o casamento, a aliança que fundamenta o social, mas também a casa-grande como uma unida de jurídico-econômica; a escravidão, um modo de produção econômica na qual o corpo do trabalhador é uma propriedade legal; e mais importante, a histórica, na qual os direitos absolutos do pa tria rc a do sobre oscorpos dos escravos ta mbém incluem o direito de usa ro corpo da escrava como instrumento sexual e o direito de reclamar como seus os filhos dessas uniões sexua is.

Estando a miscigenação no centro do texto nacional, o sujeito subalterno gendrado/racial é inscrito como exibindo uma dupla vulnerabilidade. Mais importante, a escrita do indígena e dos corpos femininos afric anos esc ravizados como os instrumentos do desejo português tomam produtiva a violência que cria o sujeito brasileiro. De acordo com Freyre, a "promiscuidade" que caracteriza a sociedade colonial resultou de uma combinação do desejo incontrolado do próprio homem português com o fácil acesso que ele tinha a o corpo da escrava. Assim, enquanto o escravo e a mulher branca tinha m sua sexualida de controlada pelo sistema patriarcal, o homem português e a escrava apareciam como os principais agentes de miscigenação (ao invés de agente e instrumento). "As mulheres negras ou mulatas", diz,

[eram] responsáveis pela precipitação da vida erótic a e da dissolução sexual dos jovens brasileiros. Com a mesma lógica se poderiam responsabilizar os anima is domésticos; a bananeira; as melancias... Quase todos eles eram os objetos sobre os quais a precocidade sexual do jovem brasileiro era, e ainda é, exercita da. ${ }^{27}$

O efeito mais importante dessa celebração da sexualidade incontrolada não foi apenas mascarar a violência inerente à escravidão. O subaltemo gendrado/ racial é duplamente vulnerável. Nem pa ixão (que embora não determinada pela razão institui um sujeito na medida em que a pessoa afeta da é determinada porcerto objeto), nem amor (que também se refere a um modo de afeição, 
mas que não parte dos limites da moralidade racional), nem consentimento (que é um privilégio do objeto racional a utodetermina do) podem ser tomados para insc revê-la como um sujeito transparente. Suas razões e paixões, a tributos de quem deseja, de um sujeito, sã o escrito s como irrelevantes na afirmação que a compara a uma bananeira, um objeto que deveria ser engolido - negado/ desintegrado -, um objeto exterior cuja apropriação é necessária para a realização do desejo do português, aquela que ele necessitava para liberar o desejo incontrolado que marca sua força produtiva especial.

Inscrevendo o subaltemo $\mathrm{racial} / \mathrm{g}$ endrado como o objeto da luxúria do português, o texto de Freyre institui uma maneira de sujeição racial, que é, a o mesmo tempo, a própria condição de possibilida de para a escrita de uma trajetória de um "eu" transparente. Na democracia racial, a miscigenação (física e cultural) escreve a negritude e a a fricanidade como "resíduos" do espírito a fricano, capturados pelos antropólogos brasileiros companheiros de Freyre, para diferenciar o sujeito nacional. Isto é, tais "resíduos" não são características determinantes, porque a diferença racial dos negros integra a narrativa da trajetória temporal do sujeito brasileiro em vulnerabilidade, como a cultura a fric a na "desa parecendo", que lhe confere c a ra c terístic a s cultura is não-determina das (a culinária e o folclore), e como a mulher escravizada, cuja sujeição é duplamente vulnerável, detemina da pelo exterior, a saber, por sua posição jurídico-econômica e por estar fora da lei (moral) do patria rca do, que, de acordo com a articulação psicanalítica do sexual, diferencia a humanidade da a nima lidade.

Dito de outra forma, a democracia racial poderia descrever a trajetória temporal do sujeito nacional para escrevê-la como uma história particular porque, em seu rela to da miscigenação, a a propriação dos corpos femininos negros permite o emprego do desejo produtivo do português, que é necessário para a escrita de uma teleologia. No entanto, o significado escatológico da miscigenação é necessário a qui para escrever o mestiç o, o sujeito brasileiro para signific ar somente a força produtiva do português. É a penas porque a democracia racial é um texto gendrado explícito, em que a escrava vulnerável escreve a força produtiva do português, que o uso do racial num texto normatiza do pelo cultural (histórico e a ntropológico) poderia escrever a teleologia de um sujeito transparente (branco/europeu) mesmo se ele pudesse a penas ser a rtic ula do como um "eu" patria rc al. Essa versão bem-sucedida do sujeito brasileiro teve um preço. Uma vez que o "Espírito" da nação condensa a cultura européia, 
mas seu corpo (c onfig ura çã o soc ial) retém a s ca rac teństic as físic as a fric a nas e (na tivas), nesta versão do texto brasileiro a negritude não pode significa rum sujeito a utodetermina do e produtivo, mesmo se subaltemo. No entanto, exatamente porque a apropriação do corpo feminino negro tomava como premissa a idéia de que apenas a branquitude/o europeísmo significa o "eu" transparente, a negritude e a africanidade que seus descendentes herdam dela continuam como significantes perigosos de uma vulnerabilidade.

\section{Dejeto}

${ }^{28}$ ARAÚJ O, 1994.

De maneira mais geral, o erotismo é contránio ao comportamento habitual assim como o gasto é contrá rio à aquisição. Se nos comportamos de acordo com a razão, busc a mos a umentar nossos recursos, nosso conhec imento, ou, geralmente, nosso poder. Somos inclinados, usando vários meios, a possuir mais. Nossa auto-segurança na esfera social está sempre ligada a o comportamento que busca o crescimento. Mas na febre da paixão sexual nos comportamos de forma contrária: gastamos nossas forças sem contabilizar, e perdemos substancial qua ntidade de energia sem controle e sem ganho. 0 prazer sensual está tão estreita mente ligado com a ruína que chama mos o momento de seu paroxismo de "la petite mort." Conseqüentemente, os objetos que evocam a atividade sexual para nós estão sempre ligados a algum tipo de desordem.

- George Bataille, A parte maldita (The Accursed Share)

Esta versão do texto brasileiro está deslocada? Caso ha ja qualquer dúvida em rela çã o à resposta correta a essa questão, em Guerra e paz, Ric ard o B. Araújo ${ }^{28}$ oferece uma leitura "pós-modema" dostextos de Freyre, que indic a como as perigosas instituições de miscigenação ainda assombram os antropólogos brasileiros. Em sua leitura da versão de Freyre da democracia racial, Araújo desafia o que diferencia a sociologia de Freyre, primeiramente (mas não a penas) em termos de sua reescrita do texto brasileiro. Ele se opõe à "acusação" de que Freyre tenha usado a miscigenação para produzir uma imagem do Brasil como um "paraíso racial" - mascarando a brutalidade inerente à escravidão - argumentando que Freyre escreve o colonizador português como híbrido, enfrentando a tarefa de reconciliar suas tendências distintas. Não haveria problema nesse argumento se Araújo não tivesse colocado hybris (que ele traduz como excesso) no centro da sociologia freyreana. Para serma is p recisa, Araújo captura uma dimensão crucial da versão de Freyre da "democracia tropical", quando ele identifica hybris como um tropo consistente na construção que Freyre faz do português, do trópico e da escravidão brasileira. Mas a figura retórica que Araújo emprega para responder ao porquê de as 
${ }^{29}$ ARAÚ 0, 1994, p. 24-25.

${ }^{30}$ SPIVAK, 1994 tendências incongruentes permanecerem numa situa ção de equilíbrio - incluind o a quela entre a natureza despótic a e íntima das relações (sociais) do escravo - toma-se um correspondente interpretativo da violência apagada na leitura de Freyre da escra va tura. Pois Araújo a rgumenta que "o excesso sexual é, de fato, o principal responsável pela criação de 'zonas de fraternização' [...] o que contrabalançou, até certo ponto, o despotismo típico da escravatura".29 Que esse excesso permaneça como um a tributo português, uma metáfora para a brutalida de, tomase irrelevante quando Araújo sugere que é exatamente a perda dessa dimensão de intimidade entre senhores e escravos que caracteriza a modemização da sociedade brasileira. Mais importante, como o projeto de Araújo é recuperar Freyre como crítico do essencialismo, uma espécie de ancestral da cosmopolita e pós-modema da modemidade, a a pologia freyreana do hib rid ismo se repete na reapropriação de Araújo, assim como o 'objeto' do desejo incontrolado (excessivo) do português permanece sendo a condição de possibilidade não para a modernidade brasileira (tropical), como Freyre escreveu, mas para escrever o brasileiro como sempre já uma configuração social pós-modema.

Na leitura de Araújo, o sujeito gendrado/racializa do emerge outra vez em sua dupla vulnerabilidade. Em contraste, o reconhecimento da posição da escrava teria leva do o autora perceberque essa libido incontida (a força da miscigenação) é, de fato, outro momento (gendrado) de violência da relação (intrinsecamente violenta) senhor/ escravo. Enquanto o desejo do sujeito feminino subaltemo - paixão, amore consentimento (ou falta dele) - não pode ser articulado no texto que (re)produz sua sujeição, sua posição silenciosa não é irrelevante. ${ }^{30}$ Toda e qualquer leitura do contexto signific ante de seu a pagamento deveria foc a liza r os seus efeitos produtivos. Se nã o o faz, a tua rá no sentido de seu apagamento, que, no ca so do Bra sil, a rticula o desejo de apagamento de cerca de metade da população. Quando a leitura pós-modema de Araújo da democracia racial estabelece uma outra versão da demanda ética de eliminar o racial da gramática política moderna, ela apaga precisamente o fato de que a miscigenação tem operado apenas como uma solução para o dilema das elites brasileiras porque significa a obliteração da diferença racial. Somente a través do reconhec imento de que esse dilema é produto das mesmas estra tégias de signific ação esta belecidas para resolvê-lo, que escreveram o Brasil e seus habitantes sempre já levemente mais escuros para habitar o domínio da exterioridade, será possível formular estratégias 
emanc ipa tória sque possa m esc reverum futuro não a penas para a grande maioria de seus habitantes, que nossa estratégia de sujeição racial escreveu não sempre já exterior, mas como chegando perto do momento da obliteração final. O que muitos hoje deploram como a violência irrestrita que está assombrando a selites bra sileiras, levando-as a se esconder em carros blindados e condomínios de alta segurança e seqüestrando o futuro de gerações inteiras de negrose mula tos brasileiros, não é mais do que a última manifestação do desejo nacional de obliterar o povo brasileiro, que, independentemente do desejo da elite pela brancura, insiste em significar o contrário. O que sugiro aqui é que o excesso que Freyre escreve e Araújo rea rticula é a penas a lgo a sercelebrado se não se consegue ler como o erótico, em Casa-Grande $\&$ Senzala, não é uma tra nsgressão, mas um outro momento da regulação produtiva - no sentido utilitário que Bata ille deplora. Mais importante, a celebração do sujeito social que ele produz, o significante da liberdade do português, de sua vontade de se engajar e sua atitude destemida perante o outro, pode a penas se sustentar se esquecemos que esse desejo produtivo é somente português, que escravos, homens e mulheres, constituem somente ferramentas, instrumentos de produção, e que, dentre as coisa súteis - o ma terial bruto - que as esc ravas produzira $m$ estava o mestiço, um objeto condenado a o consumo, um excesso a penas necessá rio porque a o português faltavam a tributos físicos ind ispensáveis à construção de uma civiliza ção nos trópicos. Agora, no entanto, na medida em que a sestruturas e os processo s econômic os globa is exig em menos e menos trabalho humano, quando menos material bruto é preciso para reproduzir a riqueza, o excesso finalmente atingiu o destino que a lógica utilitária proporciona, ele tomou-se um dejeto.

\section{Referências bibliográficas}

ANDERSON, Benedict. Imagined Communities. London: Verso, 1983

ARAÚj O, Ricardo B. Guerra e paz. Rio de Janeiro: Editora 34, 1994.

BATAILE, George. The Accursed Share. New York: Zone Books. 1993. v. II \& II.

BURLER, J udith. Bod ies that Matter. Lond on: Routledge, 1993.

FOUCAULT, Mic hel. The History of Sexuality. An Introduction. New York: Vintage Books, 1978.

FREUD, Sigmund. Outline of Psychoanalysis. London: The Hogarth Press and the Institute of Psychoanalysis, 1940.

FREYRE, Gilberto. Casa-Grande \& Senzala. Rio de Janeiro: 
José Olympio Editora, 1987.

HABERMAS, J urg en. The Philso phic al Disc ourse of Modernity. Cambridge, Mass: The MIT Press, 1987.

HEGEL, G. W. F. Phenomenology of Spirit. Oxford: Oxford University Press, 1977.

HOBSBAWN, Eric. Nations and Nationalism. Cambridge: Cambridge University Press, 1994.

OMI, Michael, and WINANT, Howard. Racial Formation in the United States. New York:

Routledge, 1994.

SILVA, Denise Ferreira da. “'Bahia, Pelo, Negro': Can the Subaltern (Subject of Racia lity) Speak?" Ethnic ities, v. 5, n. 3, Sept. 2005, p. 321-342.

"Toward a C ritique of the Socio-logos of J ustice: The Analytics of Raciality and the Production of Universa lity. Social Identities, 7, 3: 421-454, September 2001.

Homo Modernus: Raciality and the Production of the Global /Historical Consciousness. Minneapolis: University of Minnesota Press, Forthcoming.

STOLER, Ann. Race and the Education of Desire. Durham: Duke University Press, 1995.

SPIVAK, Ga ya tri Cha kra vorty. "C an the Subaltem Speak?" In: WILIAMS, Patrick, and CHRISMAN, La ura (eds.). Colonial Disc ourse and Post-Colonial Theory. New York: Columbia University Press, 1994. p. 66-111.

YOUNG, Robert. Colonial Desire. London: Routledge, 1995.

[Recebido em outubro de 2005 e aceito para publicação em janeiro de 2006]

\begin{abstract}
A Brasileira: Raciality and the Writing of a Destructive Desire
Abstract: If erotic ism, as Bataille states, disting uishes human sexuality - as it institutes the modern subject as the effect of desire - it belongs in critic al a nalyses of the conditions of production of modern subjects. For this rea son, in this pa per, I revisit artic ulations of the erotic in Freyre's version of the Brazilian national subject. I trace how eroticism produces a racial figure, the mestiç 0 , whose particularity resides in that it is a n esc ha tological object, i.e. a historic al fig ure destined to disa ppear. While this figure has been celebrated as the unifying, productive symbol of Brazilianness, it has opposite material effects. As a political/symbolic device, the mestiço institutes subaltern social subjects. This results from how miscegenation, as a historical signifier, anticipates the (physic al and symbolic ) ob literation of blacks and Indians. This, I show, results from the construc tion of the nonwhite female as an instrument (not as an object) of colonial desire. As such, it is also presupposed in the mechanisms of racial subject governing contemporary Brazil.
\end{abstract}

Key Words: Erotic ism, Sexuality, Misc egenation, Brazil, Patriarchy.

Tradução de Maria Isabel de Castro Lima Revisão da tradução por Simone Pereira Schmidt e Claudia de Lima Costa 